\section{Infiltrating hepatocellular carcinoma into the duodenum presenting with upper gastrointestinal bleeding}
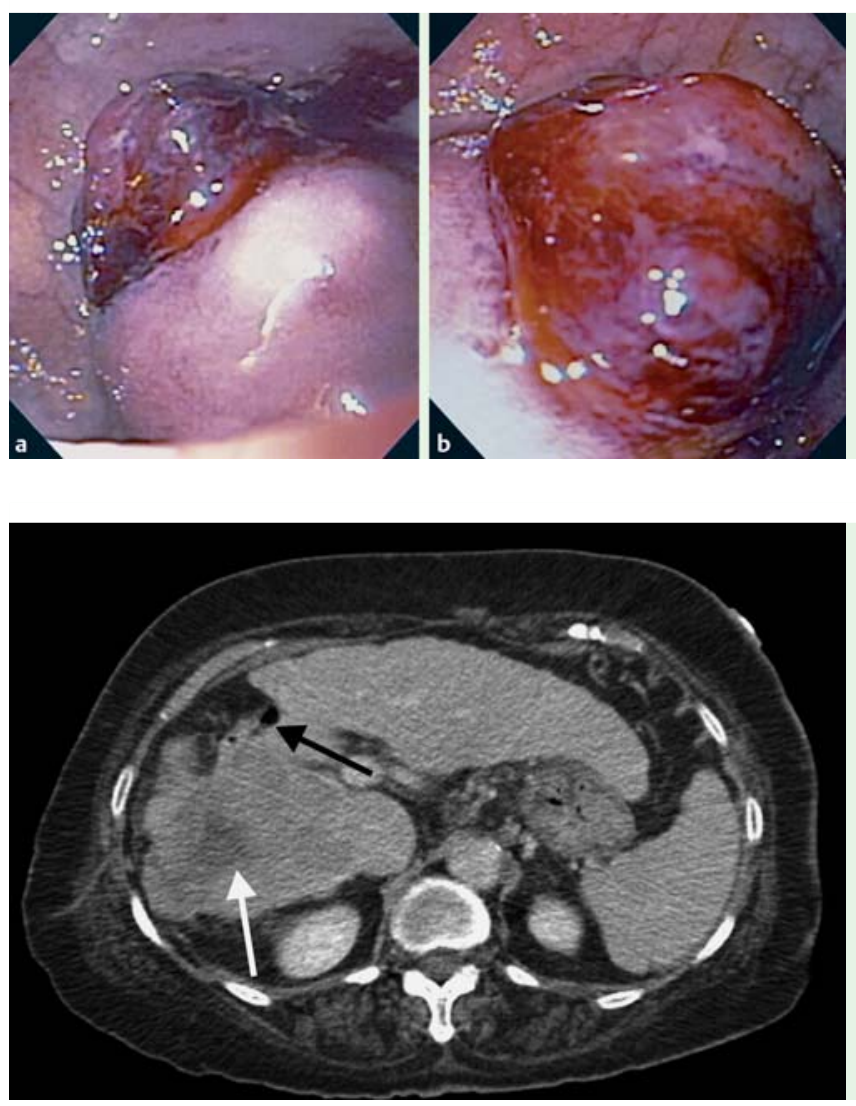

Fig. 1 a, b Endoscopic view of an infiltrating mass into the duodenal bulb with active oozing.

Fig. 2 Abdominal computed tomography (CT) scan showing a large $(8.5 \times 6.9 \mathrm{~cm})$, inferior right hepatic lobe mass (white arrow) with direct invasion into the proximal duodenum (black arrow).
Hepatocellular carcinoma (HCC) is a primary tumor of the liver that usually develops in the setting of chronic liver disease and cirrhosis. Extrahepatic spread is found in $10 \%-20 \%$ of patients at the time of diagnosis and is more common in tumors over $5 \mathrm{~cm}$ in diameter [1]. Direct invasion of the gastrointestinal tract is rare and reported to occur in $0.5 \%-2 \%$ of cases [2]. We present a case of HCC directly invading the duodenal bulb with resultant upper gastrointestinal bleeding.

A 78-year-old woman with a history of chronic hepatitis $C$ presented with 2 days duration of melena and a hemoglobin of $6.8 \mathrm{~g} / \mathrm{dL}$. Two years prior she underwent intraoperative radiofrequency ablation to three HCC lesions located in the left lateral hepatic lobe, dome of the liver, and the inferior right hepatic lobe. Interval followup imaging revealed residual tumor in the dome of the liver and the inferior right hepatic lobe, which had been treated with sorafenib.
Endoscopic findings revealed an infiltrating mass into the duodenal bulb with active oozing ( $\bullet$ Fig. 1 ).

Epinephrine $(1: 10000)$ was injected around the protruding mass with satisfactory control of bleeding. Computed tomography of the abdomen ( $\bullet$ Fig. 2 ) revealed a cirrhotic appearing liver with a large, $8.5 \times 6.9 \mathrm{~cm}$, inferior right hepatic lobe mass with direct invasion into the proximal duodenum.

HCC has been described with direct invasion into the stomach and colon with resultant gastrointestinal bleeding [3,4]. Direct invasion into the duodenum has been rarely reported [5], and upper gastrointestinal bleeding and gastric outlet obstruction is a rare presentation when duodenal invasion occurs [6]. Treatment with external beam radiation therapy has been described when gastrointestinal bleeding refractory to standard endoscopic hemostasis techniques occurs [7]. Surgical resection with a pancreas-sparing duo- denectomy or an extended left lobectomy with partial gastroduodenectomy has been successful $[8,9]$. Despite the above measures, prognosis remains poor.

Endoscopy_UCTN_Code_CCL_1AB_2AZ_3AB

\section{E. Kurtz, A. R. Miah}

Division of Gastroenterology, Long Island Jewish Medical Center, New Hyde Park, New York, USA

\section{References}

1 Yuki $K$, Hirohashi S, Sakamoto $M$ et al. Growth and spread of hepatocellular carcinoma. A review of 240 consecutive autopsy cases. Cancer 1990; 66: 2174-2179

2 Chen LT, Chen CY, Jan CM et al. Gastrointestinal tract involvement in hepatocellular carcinoma: clinical, radiological and endoscopic studies. Endoscopy 1990; 22: 118 123

3 Nicoll AJ, Ireton HJ, Crotty B. Gastrointestinal bleeding from hepatocellular carcinoma invading the stomach. J Gastroenterol Hepatol 1994; 9: $533-535$

4 Chen CY, Lu CL, Pan CC et al. Lower gastrointestinal bleeding from a hepatocellular carcinoma invading the colon. J Clin Gastroenterol 1997; 25: 373-375

5 Humbert P, Sarmiento J, Boix J et al. Hepatocellular carcinoma presenting with bleeding due to duodenal perforation by the tumor. Endoscopy 1987; 19: $37-38$

6 Mohamed AO, Joshi S, Czechowski J et al. Hepatocellular carcinoma directly invading the duodenum. Saudi Med J 2005; 26 : $478-$ 480

7 Hung HC, Huang YS, Lin CC et al. Radiotherapy in the treatment of duodenal bleeding due to hepatocellular carcinoma invasion. J Gastroenterol Hepatol 1998; 13: $1143-$ 1145

8 Cho A, Ryu M, Ochiai T. Successful resection, using pancreas-sparing duodenectomy, of extrahepatically growing hepatocellular carcinoma associated with direct duodenal invasion. J Hepatobiliary Pancreat Surg 2002; 9: 393-396

9 Hatano E, Ikai I, Shimizu M et al. Resection for hepatocellular carcinoma with duodenal invasion: report of a case. Hepatogastroenterology 2003; 50: 1034-1036

Bibliography

DOI $10.1055 / \mathrm{s}-0029-1215225$

Endoscopy 2009; 41: E308

(c) Georg Thieme Verlag KG Stuttgart · New York . ISSN 0013-726X

\section{Corresponding author}

\section{E. Kurtz, MD}

Division of Gastroenterology

Long Island Jewish Medical Center

270-05 76th Avenue

New Hyde Park

New York 11040

USA

Fax: +1-718-841-7420

leonkurtz@yahoo.com 